\title{
A Cognitive Linguistics Diagnosing Of Iraqi EFL Students' Difficulties in Using Synonyms
}

\author{
Sura Muttlak Nasser \\ University of Baghdad - Iraq \\ sura.muttlak@coeduw.uobaghdad.edu.iq
}

DOI: http://doi.org/ 10.36892/ijlls.v3i3.661

$\begin{array}{ll}\begin{array}{l}\text { Received: } \\ \text { 03/08/2021 }\end{array} & \text { Abstract } \\ \text { Accepted: } & \text { task. Learning synonyms means learning how words can be related to } \\ \text { 09/09/2021 } & \text { each other. Understanding synonyms helps students to understand the } \\ & \text { meaning of the word easily and avoid mistakes committed in synonyms } \\ \text { Keywords: } & \text { as a result of their knowledge concerning this area. Iraqi EFL students } \\ \text { lexical concept, difficulties in using appropriate synonyms. This study was } \\ \text { synonyms, } \\ \text { theory of domain } \\ \text { conducted in the Department of English, College of Education for } \\ \text { Women, University of Baghdad, to indicate first-year students } \\ \text { incompetence in using synonyms. The participants of this study, fifty } \\ \text { female students during the first semester, were chosen randomly for the } \\ \text { academic year 2019-2020. In order to achieve the aim of this study, the } \\ \text { researcher used pre and posttest as tools for collecting data. The data } \\ \text { was analyzed by the SPSS program. Figures and tables were used to } \\ \text { present the data. The present study reveals the difficulties that occurred } \\ \text { when Iraqi EFL students used synonyms. This is due to the need for } \\ \text { information about English equivalent words, then suggests suitable } \\ \text { solutions for them. Also this study reveals that the domains theory has } \\ \text { indeed been demonstrated to be effective in precisely understanding the } \\ \text { semantic domains of English lexical concepts. }\end{array}$

\section{INTRODUCTION}

English is considered as a second language in Iraq and is the most spoken language in the world, which is used for various purposes such as science, education, business ...etc. (Abbasian \& Biria, 2017). EFL learners are intended to benefit from English as an International Language (EIL) by developing a pluralistic concept of English varieties and improving their negative stereotypes and opinions toward vocabulary varieties, as well as their own (Saito, 2021). Hence, English as an international language is filled with words containing various synonyms. English has adopted different words from other languages and formed new words to express new ideas. The most important fields that EFL learners need are synonyms. Iraqi students face difficulties in using correct synonyms, i.e., English as L 2 for Iraqi students is considered a challenging matter. Furthermore, to understand synonyms, students need to realize the role and the significance of dominant synonyms and to be familiar with denotation and connotation, which refer to synonyms. 
This paper sheds light on Langacker's cognitive linguistic theory of domains (1987) to highlight vocabulary learning and to provide the synonym knowledge of EFL Iraqi students.

\subsection{Aims of the study}

This study aims at diagnosing and analyzing the errors committed by Iraqi EFL students in using synonyms to identify the difficulties of the errors.

\subsection{Problem of the study}

This study focuses on identifying Iraqi EFL students' use of synonyms. The main problem with Iraqi EFL students is the unsuitable choice of an item in the text in which it is used. Providing the correct synonym of a word is difficult concepts for Iraqi EFL students because they are too hard to guess, and have no specific rules to follow.

\subsection{Significance of the study}

This study examines English synonyms, which are considered important criteria in understanding new vocabulary items. This study will be helpful to all those who are interested in the teaching and learning process, especially those who teach English as a foreign language.

\subsection{Research questions}

1. How do Iraqi EFL students perform in terms of inducing patterns or distinguishing between synonymous words when they use a second language?

2. What are the difficulties that face Iraqi EFL students in using synonyms?

\section{LITERATURE REVIEW}

\subsection{What are Synonyms?}

The English language is rich in synonyms and is considered as a second language in Iraq, so students try to develop their vocabulary opportunity through the four skills of language teaching (writing, reading, speaking, and listening). According to Nasser (2019), these skills are important tools for EFL students and are considered the basic factors for successful academic performance in educational circles.

Synonyms (Arnold, 1986) are words that have the same or identical meaning and can be used to describe various shades of meaning, depending on the context. So, synonyms provide their users with a different type of expression tool. In other words, synonyms are types of semantic relationships between words. It can be shown when two or more linguistic constructions are used to replace each other in any context where their meanings are not influenced denotatively, such as (healthy, well, sick, and ill). Those words are examples of synonyms because they share most properties with one another.

Kazaal (2019) defines synonyms as "words or phrases that are in the same language." It means that some words in English have the same meaning but are dissimilar in their forms. Hence, Iraqi students at the University of Baghdad study English language only for a particular academic goal to meet the educational requirements (Nasser, 2019). So, these words are hard to understand for EFL in realizing how to use them correctly. Krebt (2017) declares that synonyms are words that have the same meaning, it can be called a universal linguistic phenomenon that occurs in the linguistic system of language. Saeed (2003) states that synonyms are a type of sense connection between words, in which these words show identical basic sense.

According to Edmonds \& Hirts (2002), there are two kinds of synonyms: complete synonyms and partial synonyms. Complete synonyms own similar senses and are interchangeable, whereas partial synonyms participate in their meaning aspects. Another 
difference between them is that partial synonyms do not occur due to the fact that the meaning of words occur either in monolingual or multilingual context. It has been noticed that using correct synonyms is confusing for EFL students (Liu \& Zhong, 2014; Liu, 2013; Yeh et al., 2007). This shows that learning synonym is a basic skill in second language contexts. In this scope, Alanazi (2017) states that, according to his experience as an English teacher, the performance of synonymy by Arabic-speaking students is completely neglected in teaching the English language.

Kazaal (2019) asserts that synonyms are important and helpful for some points: developing students' writing and making it active, improving students' vocabulary, forming a more interesting image in the mind of the receiver, supporting students in thinking of other ways to say the same thing, and helping students to influence someone in writing or speaking. She also sums up the benefits of using synonyms as follows: it clarifies texts and makes them more attractive, it helps to ignore boring texts, and it develops communication between a person and others. It means that learning synonyms is a critical task since Iraqi EFL students use synonyms in order to avoid repetition of the same vocabulary in their writing or speaking the English language. Iraqi EFL students were obscured by using vocabulary that has the same meaning as vocabulary which does not have close semantic connections.

Afghari \& Khayatan $(2017$, p. 122) propose that synonyms are those words which own the same or related meaning as another word. The English language contains a lot of words which can be regarded as synonymous and getting those words may be considered a very important skill in learning English as a foreign language. English as a second language requires enough knowledge of synonyms. Lyon (1996, p. 194) supposes various categorizations of synonyms, as shown in figure 1:

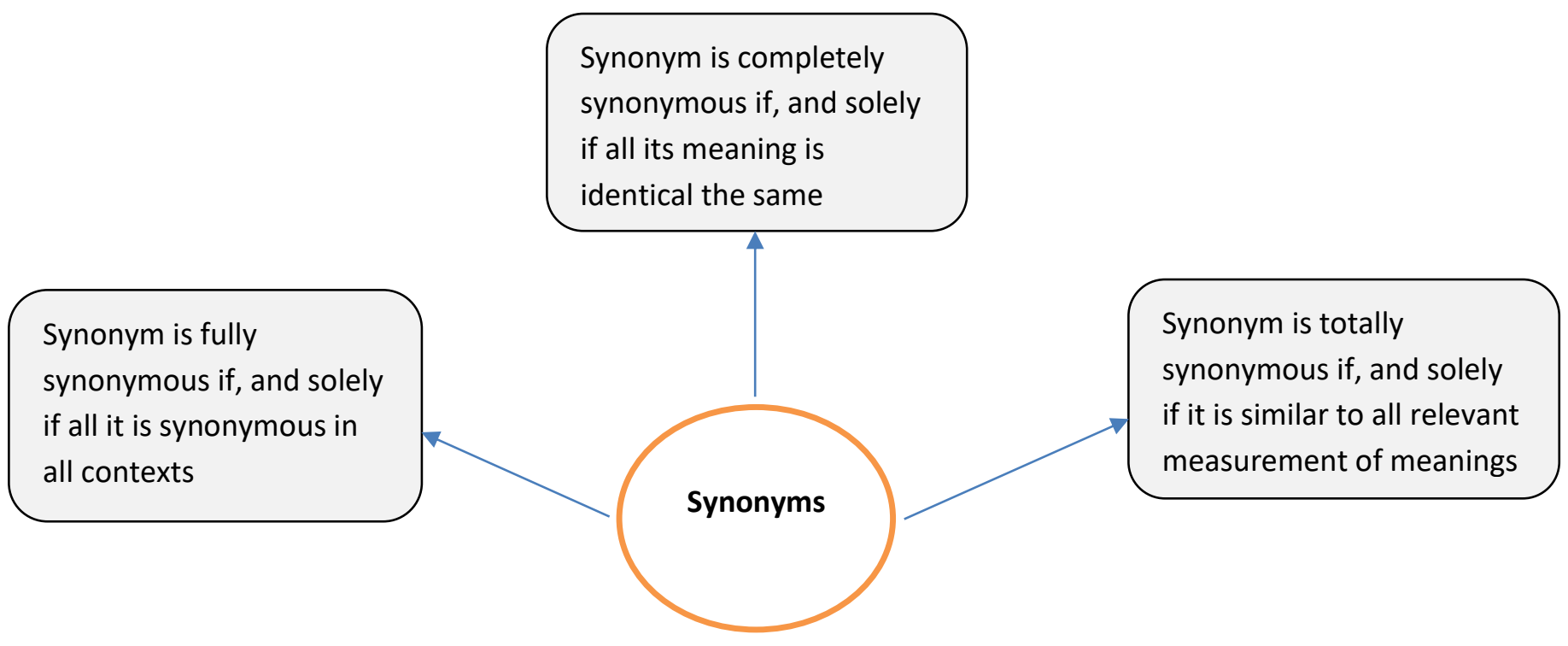

Figure (1), set by the researcher, which shows the categorizations of synonyms according to Lyons' classification (1996, p. 194).

\subsection{Cognitive Theory of Domain}

The cognitive linguistics (CL) is the basic category of function and meaning in the use of language. Nasser (2020) asserts that CL has shown a pedagogical understanding of foreign language teaching. The theory of domain by Langacker (1987) shows consideration of the theory of Frame Semantics by Fillmore. The explanation of semantics enhances students' ability to develop their vocabulary and make a link between new words and known words.

The Domain was used for the first time in (1987) by Langacker, who was affected by Fillmore's theory of Frame Semantic. Evan \& Green (2006, p. 230) assert that both Fillmore's and Langacker's theories depend on the supposition that meaning is encyclopedic, 
and that lexical sense can be recognized relying on larger knowledge information, which is named domains by Langacker.

Langacker (1987, p. 147) defines a domain as "necessarily cognitive entities: mental experiences, representational spaces, concepts, or conceptual complexes." This definition is based on humans' mental explanation of language. This shows that if a unit of knowledge construction includes background information opposed to which a lexical notion may be understood and achieved in language, then this knowledge construction can be determined as a domain.

This theory of domain is extremely intuitive and helps to obtain the meaning in both the reference and target languages. Lowe $(2008$, p.1) affirms that the domain can reinforce the quality of language usage.

Azad \& Mustafa (2018) argue that a domain indicates a context of knowledge background based on mental awareness. Furthermore, the domain deals with the assumption that meaning is encyclopedic, which covers a large combination of knowledge. The form of a domain has some aspects; any aspect is a division of a domain which is connected to a specific concept. Each aspect is described by an adequate form of language. Lexical images or concepts cannot be confirmed separately from the cognitive domains where they are embedded. For example, the words like happy, joyful, and glad. So, happy, joyful, and glad are special lexical concepts in the domain of feeling pleasure. Furthermore, without recognizing the domain of feeling pleasure, students cannot be able to use these terms correctly. In this scope, Taylor (2002, p. 439) clarifies that domains may indicate any knowledge arrangement which supplies the context for the conceptualization of a semantic unit. Hamawand (2011, p. 46) assumes that a domain deals with knowledge background dependent on mental experience. The Domain is formed by the idea that meaning is considered an encyclopedic which can contain a large combination of knowledge in great detail. The construction of a domain has some facets. Any facet is a part of a domain which is connected to a specific idea. Each facet can be presented in the correct form of language. So, lexical terms are unable to be understood separately from the cognitive domains in which they are embedded.

Evans (2007, p. 61) proposes that the main function of a domain is to show a specific type of coherent fixed knowledge context as opposed to which other conceptual factors can be recognized. For example, cold, hot, and lukewarm cannot be described without indicating the domain of temperature.

Langacker (1987) offers four factors in the theory of domains. The first factor is the typical organization of domains that form serious lexical concepts. This is called the matrix domain of the concepts. Hamawand (2011, p. 48) defines a matrix as "the set of domains which provide the context for the full understanding of morpheme." For example, the commonsense knowledge of the lexical concept cat contains its life cycle, activities, shape, and physical material, as shown in figure 2 :

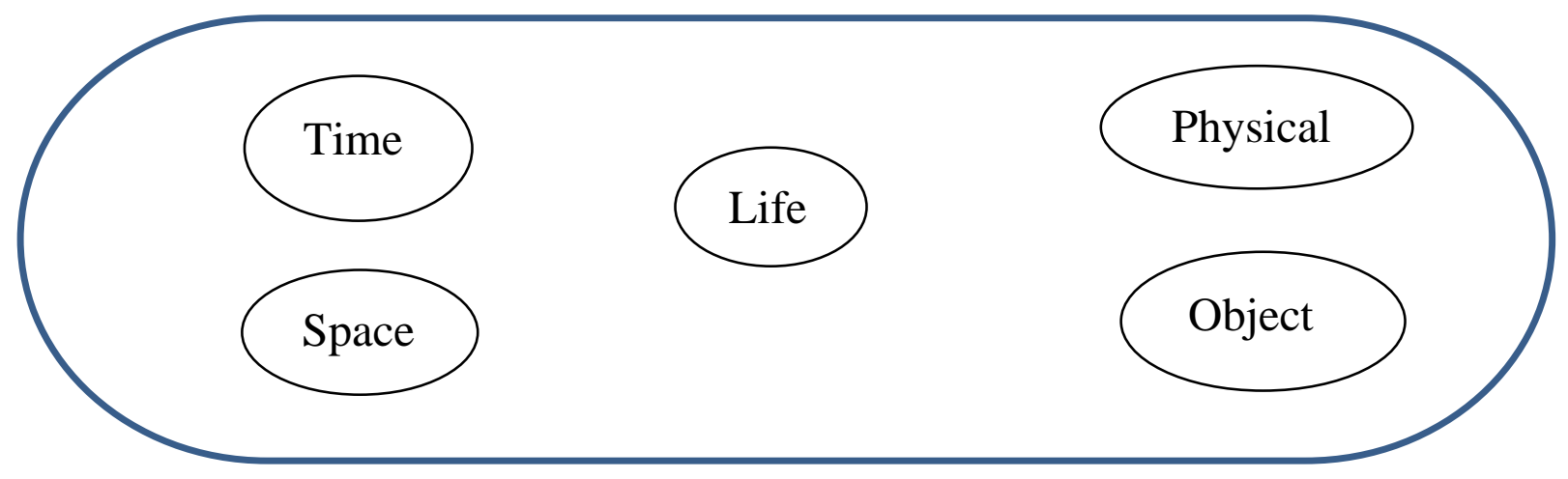


Figure 2. The figure is set by the researcher which shows the domain matrix of the word cat.

Most of the lexical sections are identified in terms of a domain matrix, but very few of them are identified by a single domain. For example, MONEY as a lexical concept contains the following domains (see figure 3): earn, save, spend, make, waste, paper, coins, finances, and invest.

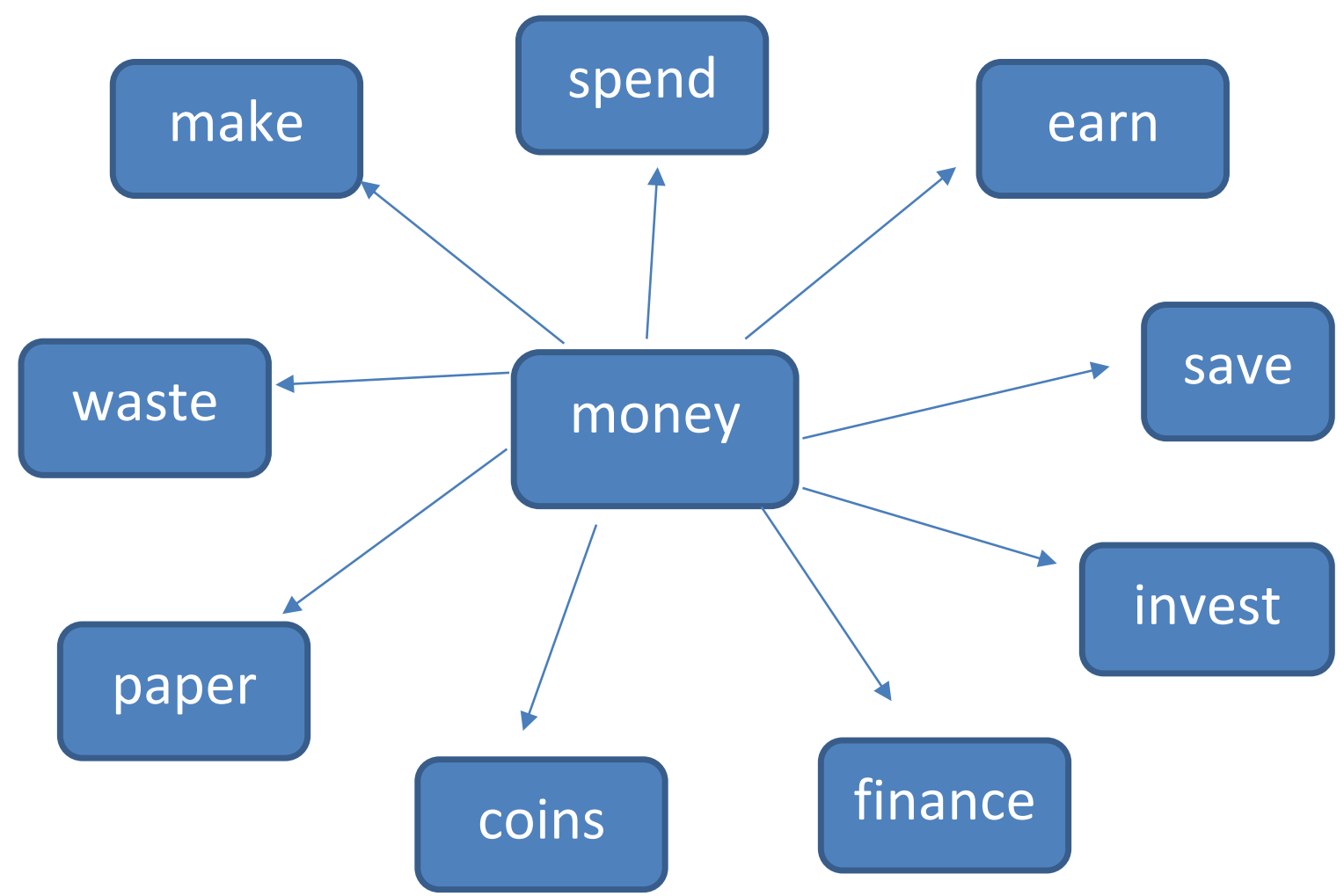

Figure (3), this figure is set by the researcher which presents the Matrix Domain of the Word Money

The second aspect that was proposed by Langacker (1987) deals with the basic and abstract domains. He improves the degree of conceptual organization, which is not clear in the theory of Frame Semantics. The distinction between the basic domains as space, time, and the abstract domains like love, hate, marriage...etc. is due to the concept of experimental grounding or embodiment. Aajami (2019) believes that "basic domains are derived from our sensory-perceptual experience with nature, while the abstract domains, which are also derived from embodied experience, are more complex in their relationship with human experience and culture." It means that abstract domains require more awareness, skills, and connections with other domains in order to be realized. For example, one may not be able to understand the word sell without knowledge of embodied experiences, such as the situation of commercial and transaction.

The third aspect is that Langacker attempts to arrange the domain in a hierarchal pattern. It shows that a specific lexical concept entails a domain below or over the hierarchy. For example, the concept of school presupposes the domain of teachers, students, books, regulation system, examinations...etc.

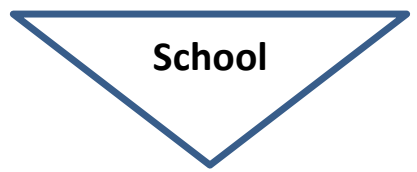




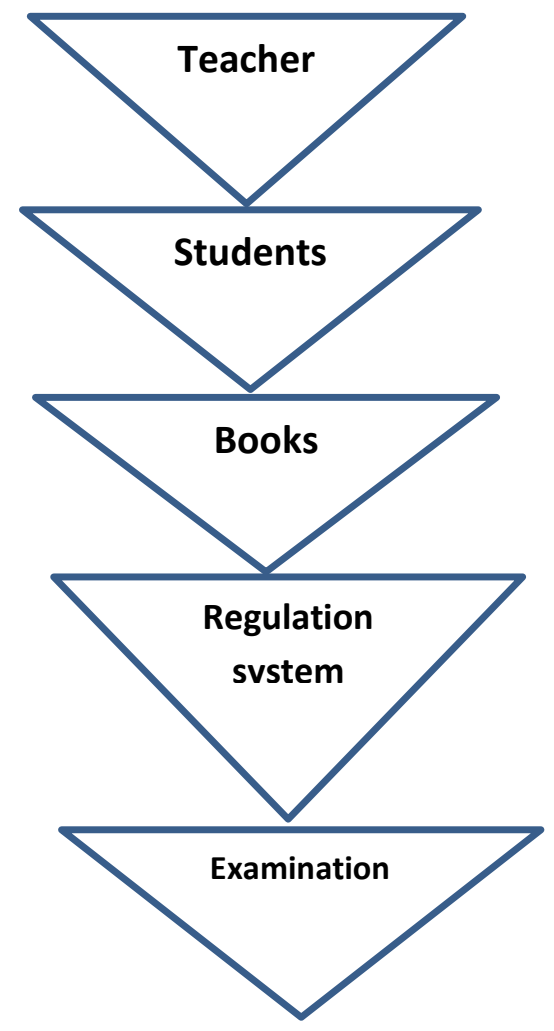

Figure (4), this figure is set by the researcher which presents the hierarchy model of domains.

Thus, Langacker's theory of domains focuses on conceptual ontogeny, which touches the form of regulation of knowledge in terms of which concepts are connected and understood by each other. Evans \& Green (2006, p. 231) state that basic domains are domains that are not understood in terms of other domains.

\section{3 previous works}

A large amount of word meanings analysis has been obtained in order to serve semantic objectives in clarifying word meanings and connections.

Study (1): This study is a research paper. The title of this article is Vocabulary Teaching Based on Semantic-Field. It was written by Cao Wangru. It was published in the Journal of Education and Learning, 2016. The writer focused in this study on the use of semantic field theory in order to enhance the vocabulary of EFL students. This theory consists of synonyms, homonymy, meronomy, hyponymy, and antonyms, and forms a semantic connection between known words and new words. The writer focuses on the significance of linguistic competence, which is influenced by word acquisition. This study finds out that learning synonyms is not an easy function in the English language since it conveys many fields in English, such as lexical, semantic, and syntactic. Also, the study reveals that the deep understanding of semantics may help EFL students to control words.

Study (2): This study is a research paper. The title of this study is On the Production of Synonyms by Arabic-Speaking EFL Learners and was written by Majed Alanazi. This article was published in the International Journal of English Linguistics in 2017. This study investigated 40 Saudi EFL students' productive knowledge of synonyms in English. It also examines whether the level of English proficiency of the participants influences their creation of English synonyms. The researcher adopted a translation test to assess Saudi EFL students' ability to produce the appropriate synonym in contextualized English sentences. 
The participants were divided into two groups; an advanced group and an intermediate group. The findings of this study show that the number of rights answers presented by the students in the advanced group was greater than that of the intermediate group, implying that their English proficiency level may have played a significant role in their responses.

\section{METHODOLOGY}

This study is an experimental study. The study will be carried out using the analytical descriptive method. Diagnostic pre and posttests for students will be used for collecting data. Fifty female students engaged in this experiment as an experimental group. The researcher focuses on explaining the related meanings of some synonyms throughout the multiple frequencies of occurrence of each word in various types within the same domain. To achieve the aim of this study, the researcher introduced the basics of the theory by using a game via a Telegram group. She forwards some words, such as woman, education, peace, college, drive... etc. The students comment on these words with single words which are connected to the meaning of the words being forwarded.

The researcher designed a pre-test to explore the meaning and frequency of the same vocabulary in various sentences. The students are asked to give polysemous meanings for the matrix domain. Also, the researcher designed a post-test to explore the different semantic domains of the same lexical aspect in the two given different positions. For example, the lexical aspect of ball in the following sentences, "the boy buys a ball" and "the boy plays with a ball'".

\subsection{Limitation of the study}

The participants of this study was fifty female first-year students at age of 18-19. The study was conducted in the Department of English, College of Education for Women, University of Baghdad. This study was achieved during the academic year 2018/2019. The study was limited to teaching writing skills from the textbook (Academic Writing from Paragraph to Essay) written by Dorothy E. Zemach and Lisa A. Rumisek, 2003.

\subsection{Procedures}

Fifty female students were engaged in this experiment as an experimental group. They did not have any previous information about the theory of domains before this experiment. To achieve the aim of this study, the researcher followed the following steps:

a. In the beginning, students were given a pre-test to assess their comprehension of the domain theory;

b. The researcher shows PowerPoint slides inside the classroom containing the basic concepts of domain theory and its characteristics.

c. After that, a report is given to them that involves a detailed discussion of the theory.

d. Students were divided into five groups. Each group involved ten students. Each group will work hard to challenge other groups.

e. The researcher organizes telegram groups in order to get a great amount of participation. The researcher gives at least two sentences, containing lexical aspects, to the students to identify the main meaning and analyze its domains. They are asked to determine the organization of these domains and receive feedback on their answers.

f. The students are asked to differentiate between domains and sub-domains of each sentence, then evoke their related domains;

g. The results of the pre and post-tests were quantitatively achieved by using SPSS (Statistical program).

\subsection{Pre-test}


The test aims to evaluate the students' abilities to explain and investigate the meaning of woman, education, peace, college, and drive. It has been shown that students do not have awareness of identifying the meaning of the previous lexical aspects. Their incompetence occurs when analyzing the domains associated with each lexical aspect. Furthermore, they were unable to differentiate the dimensions of the same lexical aspect in various sentences and were unable to recognize and produce the lexical aspects. The scores of the pre-test indicated that all students have simple information about domains theory and its approaches. It is clear that Iraqi students are determined by their initial awareness when explaining the ideas or functions that are connected to the lexical aspect. Most of the students were unable to recognize the basic, abstract, and configurational domains.

\subsection{Treatment}

Following the results of the pre-test, the treatment phase began. The target words were included in a variety of sentences. The words occur in various subjects to demonstrate their various meanings. Students were asked to examine the various meanings of each lexical aspect and identify the various related domains. They had to determine the meaning of each lexical aspect and identify the indirect and direct synonyms. Sinking into the semantics of lexical aspects helped earn greater control over the use of new words. The ability to extract a lexical aspect from a given image and explain the surrounding domains improves learners' ability to comprehend the domains of any lexical aspect. As a result, understanding the type of domain is an essential step in the semantic analysis of this technique. During class, students worked both individually and in groups, with each group preparing conceptions about a specific lexical aspect that helps in the identification of domains and their properties. They were asked to describe the dimensionality and configuration of the domains after determining whether the lexical aspects were abstract, basic, or domain matrix. They also classified the complexity of meaning or the interconnected meanings of each domain. Students took part in programs that required them to complete drawings. Then, they must investigate the domains or matrix domains of the given drawing; for example, participants were given worksheets that contained an incomplete drawing of a rabbit, and they had to complete it in the most appropriate way according to their understanding. In a subsequent step, they had to answer detailed questions or write a brief summary to explain the drawings in detail. Participants were asked to answer a project based on a given lexical aspect. The tasks were designed specifically for the students to become more involved and reveal the word meanings. The purpose of this study was to evaluate the role of domain theory in explaining the meanings of lexical concepts in relation to domains and vocabulary learning. After five weeks of treatment, the participants were permitted to take the post-test.

\subsection{Post-test}

Five weeks of discussion were spent discussing the theory of domains. During this term, the researcher focused on how to recognize the lexical aspects alone and within sentences. They have to recognize the same lexical aspect in two different sentences. During this period, the students worked in groups and were asked to give examples and explain them. The researcher showed the students diagrams (Lowe model analysis has been used to perform the domains of the lexical aspects in the diagrams) and asked them to describe these lexical concepts. When it was time for the test, they did the same work but separately. The results of the post-test showed noticeable progress in exploring the lexical aspects of the domain and distinguishing their meanings as well. The students showed a remarkable understanding of specifying the types and characteristics of domains. Furthermore, students were able to understand the surface and deep meaning of the target words. Their abilities occur in performing these words in various sentences. They were even able to discover and categorize the matrix domain. 


\section{DISCUSSION}

The results acquired from the pre and post-tests were analyzed by SPSS. The marks are not written here to safe space. Each test differentiates the achievement of all students when specifying the domains and their features. The following table shows the comparison between the pre-test and post-test.

\section{Paired Samples Statistics}

\begin{tabular}{|ll|l|l|l|l|}
\hline & & Mean & $\mathrm{N}$ & $\begin{array}{l}\text { Std. } \\
\text { Deviation }\end{array}$ & $\begin{array}{l}\text { Std. Error } \\
\text { Mean }\end{array}$ \\
\hline \multirow{2}{*}{ Pair 1 } & Pretest & 7.04 & 50 & 4.58907 & .0 .6484 \\
& Posttest & 14.72 & 50 & 4.16516 & .589904 \\
\hline
\end{tabular}

\section{Paired Samples Correlations}

\begin{tabular}{|ll|l|l|l|}
\hline & N & $\begin{array}{l}\text { Correlat } \\
\text { ion }\end{array}$ & Sig. \\
\hline Pair 1 & $\begin{array}{l}\text { pretest } \\
\& \\
\text { posttest }\end{array}$ & 50 & .78642 & .000 \\
\hline
\end{tabular}

- If the differences between both tests are less than (0.5), then the study is invalid, if the differences are more than $(0.5)$, then the study is valid.

Table (1) presents the number of students (which is 50), the average in the pre-test (which is 7.04), and the average in the post-test (which is 14.72). The students showed progress $(14.72$ out of $7.04=2.09)$. Hence, the distinction between the two means of pre and post-tests showed progress which was more than 0.5 , so this study is valid.

In comparison, the scores of both tests showed that the domain theory can make noticeable changes in students' comprehension and use of the semantics of English words.

\section{RESULTS AND FINDINGS}

The results of this study show that $1^{\text {st }}$-year students at the Department of English, College of Education for Women, University of Baghdad, reinforce their ability to learn new vocabulary by practicing the theory of domains. Moreover, the theory is based on finding the most semantically close words to the requested lexical aspect. This procedure of research and analysis can surely enhance learners' vocabulary and improve the richness of words in their minds.

The results of the pre-test indicated that all students had little information about the domain approach and its characteristics. It is clear that students build on their initial knowledge by producing ideas or uses which are connected to lexical concepts. The domain theory indicates a greater emphasis on lexical entities and relationships with closed domains. This may necessitate more time and analysis, as well as more sentence drawings and graphs to ensure their understanding of each domain.

Automatically, the students engaged in a new strategy when they think about words. Therefore, students should search for more about vocabulary and its background knowledge 
during their analysis. Undoubtedly, the students gain a thorough understanding of the semantic networks of the lexical aspects as they work through the domain theory.

\section{CONCLUSION}

This study concludes that

1- Practicing the theory of domain can enhance students' achievement in learning comprehension.

2- Practicing sense relations in teaching synonyms is useful for EFL students to improve their vocabulary.

3- Most Iraq students are not familiar with using synonyms and find difficulties in recognizing the meaning of the English lexical items.

\section{REFERENCES}

Aajami, R. F. (2019). A Cognitive Semantic Analysis of Meaning Interrelationship. Arab World English Journal (AWEJ), Vol. 10, No.1.

Abbasian, R., Biria, R. (2017). English Language Textbooks in EFL Education: Do They Improve Students' National, International and Target Culture Familiarity? Khazar Journal of Humanities and Social Sciences, Vol. 20 № 2. DOI: 10.5782/22232621.2017.20.2.49

Afghari, A., \& Khayatan, P. (2017). Collaborative Learning and Iranian EFL learners' Vocabulary Improvement through Snowball and Word-Webbing Techniques. International Journal of English Language \& Translation Studies, 5(2), 122-131.

Alanazi, M. (2017). On the Production of Synonyms by Arabic-Speaking EFL Learners. International Journal of English Linguistics, Vol (7), No. 3. doi:10.5539/ijel.v7n3p17 DOI: https://dx.doi.org/10.24093/awej/vol10no1.11

Arnold, I.V. (1986). Lexicology: Modern English Language (3rd Ed.). Moscow.

Edmonds, P., \& Hirst, G. (2002). Near-synonymy and lexical choice. Computational Linguistics, 28(2), 105-144. https://doi.org/10.1162/089120102760173625

Evans, V. (2007). A Glossary of Cognitive Linguistics. Salt Lake City: University of Utah Press.

Evans, V. and Green, M. (2006) Cognitive Linguistics: An introduction. Edinburgh: Edinburgh University Press.

Fatah, A. H., Mustafa, K. R. (2018). Nominal Grounding Elements in English: A Domainbased Account. Journal of Zankoy sulaimani-Part B / for Humanities. No (53) Jan 2018

Hamawand, Z. (2011) Morphology in English: Word Formation in Cognitive Grammar. London: Continuum International Pub. Group.

Khazaal, E. N. (2019). Investigating and Analyzing ESP College Students' Errors in Using Synonyms. International Journal of English Linguistics; Vol. 9, No. 5. doi:10.5539/ijel.v9n5p328

Krebt, D. M. (2017). An Assessment of Iraqi EFL Learners' Performance in Using Synonyms and Antonymy. Arab World English Journal (AWEJ), Vol. 8, No. 2. DOI https://dx.doi.org/10.24093/awej/vol8no2.13

Langacker, R.W. (1987) Foundations of Cognitive Grammar: Theoretical Prerequisites. (1st Vols).Stanford: Stanford University Press.

Liu, D. (2013). Salience and construal in the use of synonymy: A study of two sets of near synonymous nouns. Cognitive Linguistics, 24, 67-113. https://doi.org/10.1515/cog2013-0003 
Liu, D., \& Zhong, S. (2014). L2 vs. L1 use of synonymy: An empirical study of synonym use/acquisition. Applied Linguistics, 37(2), 239-261. https://doi.org/10.1093/applin/amu022

Lowe, I. (2008). Domain Theory of Language. SIL International, 1-43. $<$ http://www.gial.edu/GIALens/issues.htm>.

Lyons, J. (1996). Linguistic Semantics. $2^{\text {nd }}$ Ed, Great Britain:

Nasser, S.M. (2019). Iraqi EFL Student's Difficulties in Writing Composition: An Experimental Study (University of Baghdad). International Journal of English Linguistics. Vol.9, No.1. DOI:10.5539/ijel.v9n1p178

Nasser, S.M. (2020). A Cognitive-Semantic Analysis of Preposition on: An Experimental Study at University of Baghdad. Arab World English Journal (AWEJ). Vol.11. No.3. DOI: https://dx.doi.org/10.24093/awej/vol11no3.32

Saeed, J. (2003). Semantics. (3rd Ed.). Oxford: Wiley Blackwell.

Saito, Arifumi. (2021). Factors Influencing EFL Learners' Attitudes toward English Varieties. International Journal of Language and Literary Studies. Vol. 3. No. 2. DOI:http://doi.org/ 10.36892/ijlls.v3i1.623

Taylor, J.R. (2002). Cognitive Grammar. Oxford: Oxford University Press. University Press Cambridge.

Wangru, C. (2016). Vocabulary Teaching Based on Semantic-Field. Journal of Education and Learning, 5, 63-71. China Henan Polytechnic University. doi http://dx.doi.org/10.5539/jel.v5n3p64.

Yeh, Y., Liou, H., \& Li, Y. (2007). Online Synonym Materials and Concordancing for EFL College Writing. Computer Assisted Language Learning, 20(2), 131-152. https://doi.org/10.1080/09588220701331451

Zemach, D. E., \& Rumisek, L. A. (2003). College Writing from Paragraph to Essay. Macmillan.

\section{$\underline{A U T H O R ' S B I O}$}

Sura Muttlak Nasser is an instructor of linguistics at the Department of English, College of Education for Women, University of Baghdad, Iraq. Her major research interests involve English language studies, and applied Linguistics. 